\title{
Repairability Redux
}

\section{I wrote about repairability in the February 2020 issue of Communications (p. 7) and here I am at year's end harping on the same topic. My excuse is COVID-19. I have been}

at home for the past six months while my normal schedule would have had me on the road three weeks out of four. Of course, like many of you, I have been all over the world-virtually-since mid-March. There are days when I can visit Australia and Austria and be home in time for dinner. So, what does that have to do with stuff that breaks? Mostly, I am actually here when it does. Under more normal conditions, my wife would have to call a repair person to fix or replace a broken item. Now that I am home, I am sometimes the one who discovers the problem, or I am told about it before a repair service gets the call. I am an engineer of sorts, so broken things attract my attention. Engineers love problems to solve. "Fix me! Fix me! You can do it!" Of course, if you are like me, you go to the hardware store three times: first to get the stuff you need, second to get the stuff you forgot, and third to get the stuff you need to fix what you broke. My basic rant is that manufactured goods today do not seem to take into account the possibility of repair.

Case in point: a broken soap dispenser. Expensive, shiny chrome built-in kitchen soap dispenser whose $<$ insert adjectives $>$ spring gave out. OK, no problem. Look up replacement parts on the Internet. Found it! Only $\$ 4.79$ too. I ordered the part and it arrived in the mail a few days later. OK, just pull out the old one and slip in the new one ... Hmm. The new siphon has a diameter of .29 inches. The hole is .25 inches. $<$ Many bad words $>$. Why didn't they provide diameter specifications? Well, the original parts are 22 years old and I guess they changed sizes somewhere in between. Maybe I can sand down the .29-inch tube ... Nope, can't do that without making the plastic tube too brittle. Time to call my "go-to engineer" friend who has a $\$ 30,000$ Computer Numerical Control (CNC) machine that can pretty much mill anything.

This CNC thing has a bazillion interchangeable drills and other gadgets for making measurements accurate to a ten thousandth of an inch. The machine is programmable to carry out complex milling operations on a variety of materials including my chrome-plated brass soap dispenser fixture. Measuring carefully, we are going to drill out the .25-inch hole until it is .29 inches in diameter so the new siphon tube will fit snugly into the enlarged hole. Here's the right

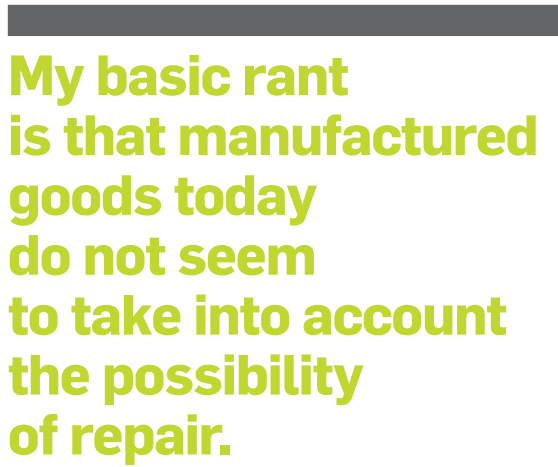

drill bit-\#108-set for 6000 RPM. Holey Moley! The drill bit got yanked out of the chuck! My engineer friend says, "Brass grabs like that." OK, new plan. Let's get a much smaller drill bit and program the machine to ream out a larger hole by making a circular traverse multiple times, drilling deeper on each traverse. Sonfagun, that works! Habemus soap dispenser!

In the last several weeks I have encountered several similar problems with "replacement parts" that don't quite fit the <ancient $>$ piece of equipment I am trying to repair. I am beginning to appreciate Cuban ingenuity. Have you seen all those cars from the 1950s in Havana? I think manufacturers today should take lessons from the LEGO company. They have produced interchangeable LEGO parts since 1932. If you are going to make products that are intended to last for decades, you should maintain sparepart compatibility for the lifetime of the product. That's what standards are for. Maybe 3D printing is a partial solution for some products since printing the part on demand might be less expensive than maintaining inventory. I think my basic complaint is that if something is advertised as a replacement part, it should really be a replacement part that fits. Well, there is always eBay, I suppose. Thanks for listening.

Vinton G. Cerf is vice president and Chief Internet Evangelist at Google. He served as ACM president from 2012-2014. 